\title{
A Case of Temporal Lobe Abscess Following Mastoidectomy
}

\author{
Jin-Young Goh ${ }^{1}$, Chan-Hwi Park ${ }^{2}$, Il-Woo Lee ${ }^{2}$, and Se-Joon Oh ${ }^{2}$ \\ ${ }^{1}$ Department of Otorhinolaryngology-Head and Neck Surgery, Pusan National University Yangsan Hospital, \\ Pusan National University School of Medicine, Yangsan; and \\ ${ }^{2}$ Department of Otorhinolaryngology-Head and Neck Surgery, Pusan National University Hospital, Busan, Korea
}

\section{유양동 수술 후 발생한 측두엽 농양 1 예}

고진영 ${ }^{1} \cdot$ 박찬휘 $^{2} \cdot$ 이일우 $^{2} \cdot$ 오세준 $^{2}$

부산대학교 의학전문대학원 양산부산대학교병원 이비인후과학교실, ${ }^{1}$ 부산대학교병원 이비인후과 ${ }^{2}$

\author{
Received November 1, 2013 \\ Revised December 23, 2013 \\ Accepted January 2, 2014 \\ Address for correspondence \\ Se-Joon Oh, MD \\ Department of Otorhinolaryngology- \\ Head and Neck Surgery, \\ Pusan National University Hospital, \\ 179 Gudeok-ro, Seo-gu, \\ Busan 602-739, Korea \\ Tel $+82-51-240-7336$ \\ Fax $+82-51-246-8668$ \\ E-mailo3jdoc@hanmail.net
}

We report a case of complicated temporal lobe abscess following mastoidectomy. The patient complained of a headache after surgery, however, he was discharged as his symptom was considered to be a common postoperative headache. He revisited our due to a generalized tonicclonic seizure, and the CT and MRI findings suggested the diagnosis of temporal lobe abscess. The patient was successfully treated with antibiotics instead of surgical treatment. Although the cerebral abscess following mastoidectomy is extremely rare, it is necessary to pay attention to it. Particularly when the patient complains of a headache, it is important to consider the aspects of headache carefully. Bone defect in tegmen tympani and exposure of dura will increase the risk of cerebral abscess, therefore careful caution is required in the presence of lower dura mater. Korean J Otorhinolaryngol-Head Neck Surg 2014;57(6):411-4

Key Words Brain abscess · Tympanomastoidectomy.

\section{서 론}

유양동 절제술은 이과영역에서 흔히 시행하는 수술이지만, 중이 및 유양동과 그 주변 조직에는 중요한 구조물이 많이 있 기 때문에 때때로 심각한 합병증이 발생하기도 한다. 유양동 절제술 후 발생한 뇌농양에 대해서는 외국에서는 소뇌농양, 대뇌 측두엽 농양, 측부정맥동 혈전을 동반한 뇌농양 등이 보 고된 바 있다. ${ }^{1-4)}$ 저자들은 유양동 절제술 후 퇴원 당시 환자가 두통 및 후이개부위의 통증을 호소하였는데 이를 단순한 수 술 후 통증으로 생각하고 퇴원시켰으나 술 후 10 일째 측두엽 농양이 발생한 증례를 보고하고자 한다.

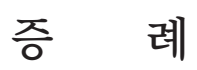

14세 남자 환자가 내원 1년 전부터 호전과 악화를 반복하는
양측 귀의 이루 및 이통을 주소로 본원을 방문하였다. 내원 당 시 신체검사 결과 양측 고막에는 고막이완부의 함몰 및 천공 이 있었고, 회백색의 진주양 광택을 가지는 조직파편이 함께 관찰되었다. 이전에 반복적인 이루의 병력이 있었으나 외래 방 문시에는 고막이 건조한 상태였다. 순음청력검사 결과 4분법 상 우측은 골도 $4 \mathrm{~dB}$, 기도 $30 \mathrm{~dB}$ 로 골도기도차가 $26 \mathrm{~dB}$ 이었 으며, 좌측은 골도 $15 \mathrm{~dB}$, 기도 $18 \mathrm{~dB}$ 로 골도기도차는 $3 \mathrm{~dB}$ 이 었다. 측두골 단층촬영을 시행한 결과 양측 모두 중이에서 유 양동 전체에 걸쳐 혼탁하였으며, 유양동은 경화되어 있었고 우측의 고실천장은 좌측에 비해 낮게 형성되고 있었다(Fig. 1). 상고실의 만성 진주종성 중이염으로 진단하였으며 청력이 더 떨어지는 우측을 먼저 수술하기로 하였다. 공동폐쇄 고실유양 돌기 절제술 및 고실성형술 I형(intact canal wall tympanomastoidectomy with tympanoplasty type I)을 시행하였다. 수술 소견상 유양동과 상고실은 진주종으로 가득 차 있었고 분 
Fig. 1. Preoperative images. Temporal bone axial $(A)$ and coronal $(B)$ CT shows destructive changes of both ossicles and scutum. And there also is hanging of tegmen tympani on right temporal bone. It is consistent with bilateral chronic otitis media with cholesteatoma.
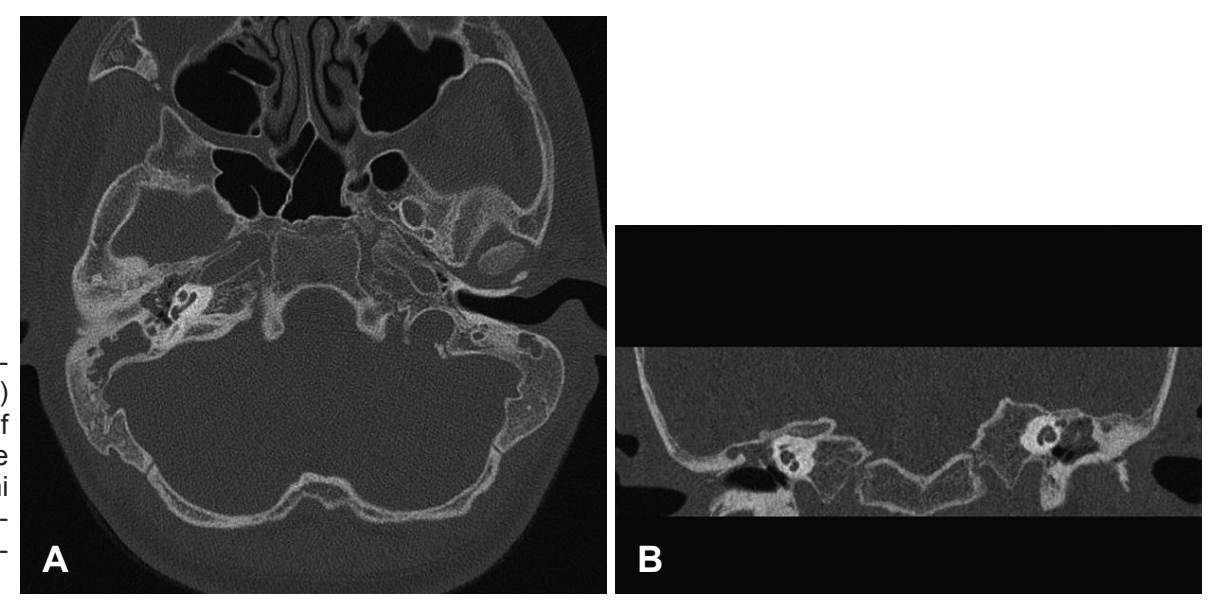
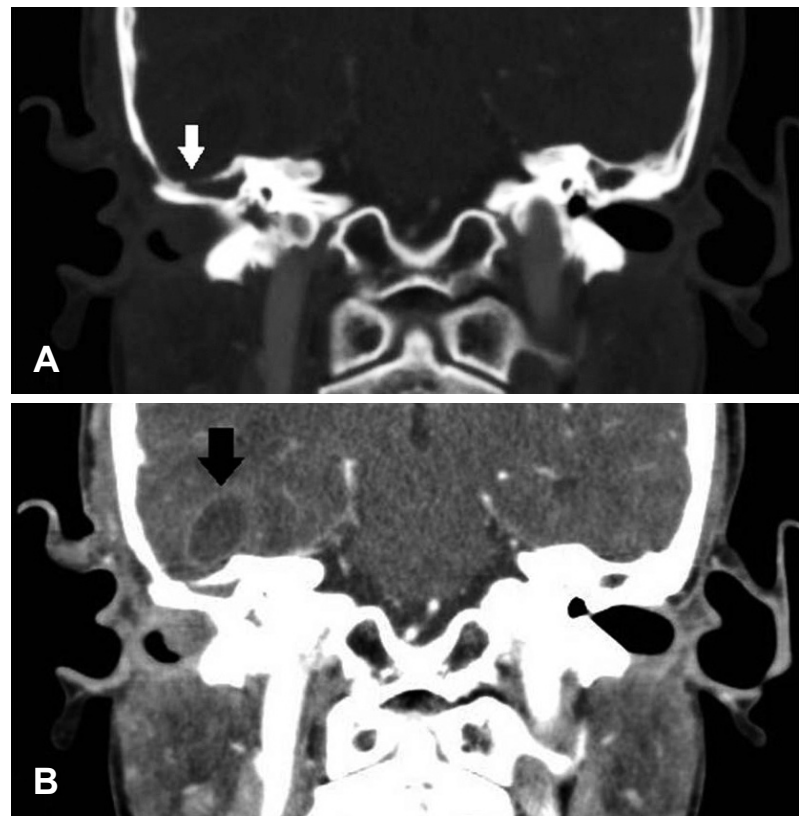

Fig. 2. Post-operative CT image. Coronal CT bone setting view (A) and contrast enhancing view (B) shows the localized bony defect in the right tegmen tympani (white arrow) and temporal lobe abscess and accompanying edema (black arrow).

비물은 관찰되지 않아 균동정을 시행하지는 않았다. 중이내에 서는 진주종이 침골의 긴 돌기까지 붙어있었다. 술 전 측두골 컴퓨터단층촬영을 통해 고실천장이 낮다는 것을 인지하고 있 었지만 수술도중 고실천장의 결손이 발생하였다. 고실천장 결 손의 크기는 $4 \times 7 \mathrm{~mm}$ 였으며 경막이 노출되었지만, 경막 자체 의 손상은 없어 다른 조치는 취하지 않았다. 진주종을 제거한 후 이주연골을 채취하여 일부 결손된 상고실 부위를 폐쇄하 고, 고막성형술을 시행하였다. 1주간 입원 후 퇴원하였으며 환 자는 경미한 후이개부위 통증을 호소하였지만 수술 부위에 서 염증소견은 관찰되지 않았고, 발열, 뇌압상승징후, 뇌막자 극 증상은 없었다. 따라서 단순한 수술 후 통증이라고 판단되 었으며 항생제 및 진통제를 처방받고 퇴원하였다. 하지만 퇴원
3일 후 심한 두통이 발생하였고, 하루 후에 갑자기 전신긴장간 대발작(generalized tonic-clonic seizure)가 발생하여 본원 응급실을 방문하였다. 측두골 전산화단층촬영상 관상면에서 고실천장의 결손이 있었으며(Fig. 2), 뇌 자기공명영상 촬영에 서 우측 측두엽에 $2.2 \times 1.0 \mathrm{~cm}$ 크기의 부종을 동반한 테두리 조영증강을 보이는 병변이 관찰되었고 조영증강(contrast enhancement)시 강한 조영증강이 보여 뇌 농양에 합당한 소견이 었다(Fig. 3). 환자는 즉시 소아청소년과로 의뢰되었으며 당일 입원하여 반코마이신(vancomycin), 메트로니다졸(metronidazole), 세포탁심(cefotaxime)을 경험적으로 투여하였다. 외 이도 패킹을 제거하니 고막에서 분비물이 있었지만 화농성은 아니었다. 균동정을 위해 혈액 배양 및 고막주위의 분비물의 세균배양 검사 결과는 모두 메티실린내성황색포도상구균(methicillin resistant Staphylococcus aureus)이 동정되었다. 항 생제를 투여 후 환자의 두통은 바로 감소하기 시작하였고 더 이상의 발작 등의 신경학적인 소견은 없었다. 약 1 개월간 입원 하면서 경정맥 항생제 치료를 지속하였으며 추적 자기공명영 상에서 뇌 농양의 감소 소견을 보였다. 그 후 1 개월 후의 추적 자기공명영상에서는 염증 소견은 거의 남아있지 않았다. 6 개 월 후 반대측을 계획대로 수술을 하였다.

\section{고 찰}

지금까지 만성 중이염 수술 후 발생할 수 있는 합병증으로는 청력감소, 현훈, 안면마비, 이명, 뇌경막 노출 및 뇌척수액 누출 등이 잘 알려져 있다. 이외에도 뇌출혈, 뇌경막 농양(subdural abscess), 횡정맥동 혈전염(lateral sinus thrombophlebitis) 등 의 심각한 중추합병증, 뇌기저 골수염(skull base osteomyelitis)도 드물게 보고되기도 하였다. ${ }^{5,6}$ 일반적으로 중이수술 후 발 생하는 뇌 농양은 해부학적으로 측두엽과 소뇌에 주로 발생하 며, 그동안 보고된 예에서도 1 예를 제외하고는 모두 소뇌 및 측 

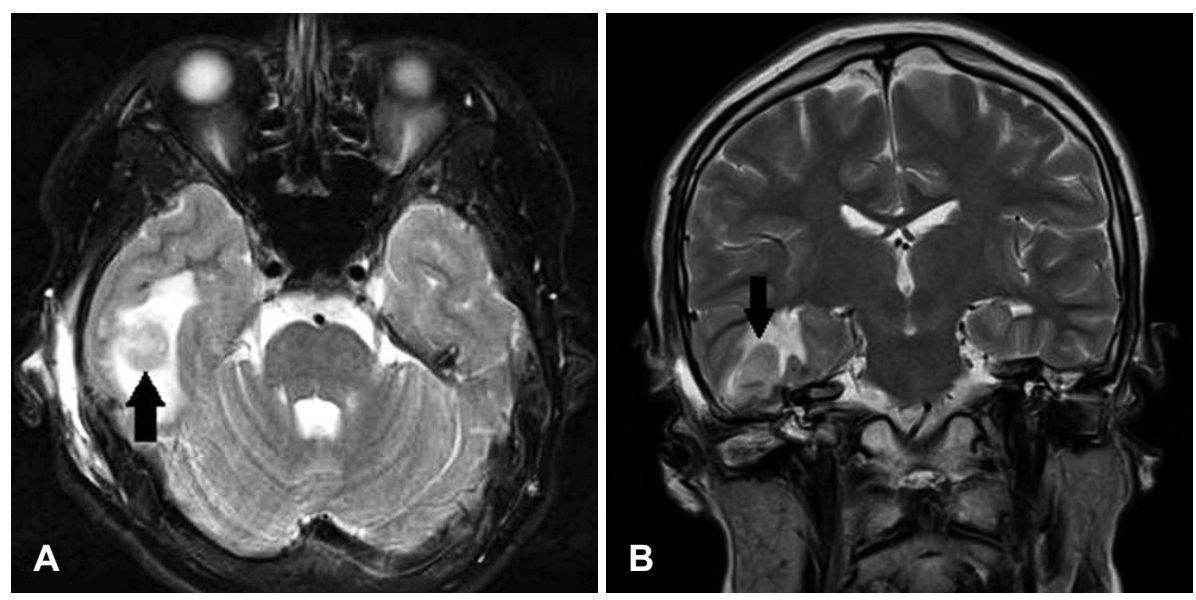

Fig. 3. Post-operative temporal MRI images. Axial (A) and coronal (B) MRI show that there are thin rim enhancing nodule and accompanied by peripheral edema (black arrows). It is consistent with the temporal lobe abscess.

두엽에 발생하였다. ${ }^{1-3)}$

일반적으로 대부분의 뇌 농양 환자는 증상이 발생한 지 11 12 일 후에 병원으로 오는 것으로 알려져 있고, 전형적인 3대 증 상은 두통, 고열 및 국소 신경학적 증상이 $50 \%$ 미만의 환자에 서 관찰되며, 가장 흔한 증상은 두통으로 전체 환자의 $75 \%$ 이 상에서 나타난다. 두통은 한쪽 또는 전체적으로 지속적이고 묵직하며 찌르는 듯한 양상을 나타내며 점점 심해지면 치료 에 잘 반응하지 않는다고 하며, 열이 없다고 진단을 배제해서 는 안 되며, 환자의 15 35\%에서 국소 또는 전신 경련이 새로 발생한다고 알려져 있다.

유양동수술 후 두개내 농양이 발생하는 시기는 그동안 보 고된 논문들을 살펴보면 주로 짧게는 5 일에서 길게는 5 주까 지 다양하였지만 2009년 국내에서 수술 후 13년째에 뇌 농양이 발생할 수 있음을 보고하여 시간이 많이 경과하더라고 간과할 수 없음을 알려주고 있다. 저자들의 경우 술 후 10 일째에 발생 하였지만, 두통이 5 일째부터 발생한 것을 볼 때 이전부터 염증 의 두개내 파급이 시작되고 있었던 것으로 추정된다. 이 시기 에 환자가 두통을 호소함에도 두통의 양상에 대해 자세히 평 가하지 않고, 또한 두개내 병변에 대해 자세히 평가하지 않은 것은 일반적으로 수술 후 환자들이 두통을 많이 호소하기 때 문에 중요성을 간과하였기 때문이라고 생각된다. 전형적인 술 후 통증과 뇌 농양에 의한 통증을 구분할 수 있는 기준은 문 헌상 나와있지 않았으나, 일반적으로 술 후 두통 및 이통은 술 후 첫째날에 가장 심하며, 점차 호전양상을 보이고 통증이 진 통제에 쉽게 반응을 하는 경향이 있다. 하지만 저자들이 경험 하였던 환자에서는 두통이 술 후 5 일경부터 나타나기 시작하 여 점차 악화되면서 진통제에도 반응이 약하였다. 수술한 지 일 정한 시간이 지나 두통이 점차 악화하면서 진통제에 반응이 떨 어진다면 이성 농양을 의심하는 것이 반드시 필요할 것으로 사 료된다.

두개내에 발생하는 합병증은 일반적으로 귀에서 발생한 염
증이 두개에 존재하는 선천적 또는 후천적인 결손부위를 통 해 파급됨으로써 발생하거나, 혈전염이 생긴 후 두개내로 파급 되어 발생한다. ${ }^{8)}$ 그렇다면 수술 중 고실천장(tegmen tympani) 결손 및 경막 노출이 술 후 중이내 균의 두개내로의 파급 경로 가 될 수 있다. 또한 유양동 절제술을 고실성형술과 함께 시행 하는 경우 고실성형술이 유양동 내의 염증의 배출을 억제할 수 있어 두개내로의 파급을 촉진할 수 있다. ${ }^{3)}$ 결국 배출이 잘 되는 것이 두개내 합병증을 줄이는 데 가장 중요할 것으로 보 이며, 이와 더불어 술 중 염증성 육아조직, 잔존 진주종을 완전 히 제거하여 염증의 초점을 제거하는 것 또한 그에 못지 않게 중요할 것이라고 사료된다. 특히 낮은 고실천장으로 경막노출 이 발생하게 되면 더욱 더 주의를 기울여야 하므로 술 전에 측 두골 컴퓨터단층촬영의 관상면을 자세히 관찰하여 낮은 고실 천장을 미리 숙지하는 것이 중요하며, 그럴 경우 유양동 절제 술 중에 병변을 최대한 완전히 제거하고 경막이 과도하게 노출 되고 손상받는 것을 피하는 데 조심해야 한다. 그리고 경막이 노출된다면 술 중에 측두근막이나 얇은 골판 같은 다른 조직 등으로 결손부위를 재건해 주었다면 두개내 합병증의 가능성 이 줄었으리라 생각된다. 만약 술자가 병변을 완전히 제거하지 못하고 경막이 노출되어 두개내 합병증이 발생할 가능성이 있 다고 생각되면 고실성형술은 단계적으로 하는 것이 한 방법이 될 수 있다. ${ }^{3)}$ 저자들의 경우 환자의 고실천장은 낮았고, 술 중 경막 노출이 발생하였으므로, 이것이 두개내 파급 경로가 된 것으로 강력히 의심이 된다.

일반적으로 뇌 농양의 가장 적절한 치료는 고단위 항생제 투 여 및 신경외과적 배농이다. 본 증례는 패킹을 제거하였을 때 분비물이 거의 없었고 염증이 귀를 통해 배출되고 있는 소견 이 보이지 않아, 지금까지 보고된 다른 증례들이 대부분 수술 적 치료를 시행한 것과 달리 약물치료를 먼저 시행하였다. 물 론 생체징후는 안정적이었고, 특히 염증 조절이 되지 않는다면 수술을 하기로 신경외과와 계획이 되어 있었지만, 항생제를 통 
해서 증상이 호전하는 경과를 보여 수술을 시행하지는 않게 되었다. 하지만 뇌 농양의 단계에 따라 치료 방법이 달라질 수 있다. 일반적으로 항생제가 매우 효과적이지만 농양 주변에 피 막이 형성되면 항생제에 반응이 떨어져 수술적 방법이 필수적 이라는 보고도 있었다. ${ }^{7)}$ 따라서 유양동 절제술 후에 발생하는 뇌 농양은 매우 드물지만, 술 후 환자의 두통이 진통제에 반응 하지 않고 점점 악화하는 양상을 보인다면 언제든지 의심을 할 수 있어야 한다. 수술 후 뇌 농양이 발생하였을 때는 무조건 개두술 및 유양돌기 절제술을 시행하기 보다는, 환자 개개인 의 전신상태 및 항생제에 대한 반응, 영상학적인 진단에 따라 약물치료를 통해서도 호전될 수 있음도 고려해야 할 것이다.

\section{Acknowledgments}

This work was supported by clinical research grant from Pusan National University Hospital 2014.

\section{REFERENCES}

1) Migirov L, Eyal A, Kronenberg J. Intracranial complications following mastoidectomy. Pediatr Neurosurg 2004;40(5):226-9.

2) Garayev A, Talyshinskiy A, Büntzel J. [Otogenic cerebellar abscess - two case histories]. Laryngorhinootologie 2007;86(9):660-3.

3) Yin T, Ren J, Lu Y, Chen X, Wang Y, Huang F. An unusual case of complicated temporal lobe abscess following tympanomastoidectomy. Int J Clin Exp Pathol 2013;6(7):1445-7.

4) Kim NG, Jeon EJ, Kim DH, Park YS. A case of intracranial abscess after mastoidectomy. Korean J Audiol 2009;13(3):264-7.

5) Kangsanarak J, Fooanant S, Ruckphaopunt K, Navacharoen N, Teotrakul S. Extracranial and intracranial complications of suppurative otitis media. Report of 102 cases. J Laryngol Otol 1993;107(11): 999-1004.

6) Kwon MS, Ahn JH. Two cases of skull base osteomyelitis after mastoidectomy. Korean J Otorhinolaryngol-Head Neck Surg 2009; 52(3):279-83.

7) Agrawal A, Pratap A, Singh I, Kumar A, Shrestha S. Cerebellar abscess following mastoidectomy for chronic otitis media. Pediatr Neurosurg 2007;43(4):327-9.

8) Seven H, Coskun BU, Calis AB, Sayin I, Turgut S. Intracranial abscesses associated with chronic suppurative otitis media. Eur Arch Otorhinolaryngol 2005;262(10):847-51. 